\title{
The Coxford Lecture Seek the Good: Professional Trust, Justice, and the Rule of Law
}

\author{
David Johnston ${ }^{1}$
}

When I was Dean of Western Law about 40 years ago, I'd deliver a welcoming address to each new crop of students. I'd open my remarks with a question: "Is law just?" To answer that deceptively short question, I'd suggest we needed to unpack two words in it-law and just.

The rule of law is something finite, something with borders, something that's made up of things we can experience, evaluate, and understand-a constitution, statutes, courts, rules of evidence and procedure. A sense of justice is something else entirely. It's infinite, without borders, made up of things we don't fully understand, can't always evaluate, and won't completely realize.

To put law and justice into sharper relief for the students, I'd raise the example of the Soviet Union. That country under Lenin, Stalin, Khrushchev, and the rest had a constitution, laws, and a court system. Was any of that meant to deliver justice for the country's citizens? That's a rhetorical question if there ever was one. The example reveals that the rule of law and a sense of justice aren't the same thing.

We have further examples right now that illuminate the difference between law and justice. Turkey, Venezuela, and North Korea all have laws and legal systems. Do the laws in those countries make them just places? Even in democracies such as ours, we have laws and a legal system. Yet is our country always and fully just? Ask an Indigenous person that question and see what answer you get.

Those examples, while real, still don't give us a clear idea of the gap between law and justice. So, to shine an even brighter light on the distinction, I'd ask those Western Law students to watch the film version of To Kill a Mockingbird. Set in Jim Crow Alabama, the film hinges on the trial of Tom Robinson, an AfricanAmerican sharecropper accused of raping a white woman. All the mechanics of a criminal trial under the principles of English common law and the mechanics of Alabama's legal system are followed scrupulously-judge, jury, lawyers for the defense and prosecution, rules of evidence, and procedure. Yet the trial of Tom Robinson is a shameful exercise in justice denied-a fact that's visible to all who participate in and attend the trial, and of course visible to all who watch the movie or read the novel on which it's based. The trial is a tool to maintain a racial

1. The Right Honourable David Johnston, Canada's 28th Governor General 2010-2017, delivered the 10th Annual Coxford Lecture on Wednesday, March 27, 2019 at Western Law. 
hierarchy in the state - to actively deprive justice from a group of people; certainly not a means to strive toward it.

By placing this tangible example in their minds, I'd hope the students would understand the yawning gap that can exist between the rule of law and justice, and to realize that the rule of law by itself doesn't guarantee justice. At their best, a constitution, laws, and a court system are instruments we shape and wield to move closer to justice.

I've learned over the many years since I spoke with those Western Law students that this lesson isn't one for budding lawyers alone. All of us in the legal profession-young and old, wet behind the ears and long in the tooth-must be lifelong learners. And that kind of education requires us to ask ourselves regularly: "Is law just?" All of us. Including me. In fact, old lawyers are among the first to neglect basic principles such as the gap that separates the rule of law and a sense of justice.

When I was asked to serve as Governor General of Canada, I discovered I had much to relearn. Despite my background as a law student, professor, and dean, I had to revisit the legal principles and conventions of our constitution, especially as they relate to the authority and function of the Crown in Canada. My re-education enabled me to develop an even deeper admiration for how precious the rule of law is in our country, how thin and vulnerable its veneer can be, and how vital it is in moving closer to justice.

Even more, my re-education revealed for me anew that the study and practice of law is a hollow pursuit if we don't use it to strive toward justice. When I consider this need, Hugh MacLennan's analogy comparing gardens to civilizations comes to mind. His words-from his novel Voices in Time-are worth quoting in full:

In the relatively rare periods in the past that we call civilized, people understood that a civilization is like a garden cultivated in a jungle. As flowers and vegetables grow from cultivated seeds, so do civilizations grow from carefully studied, diligently examined ideas and perceptions. In nature, if there are no gardeners, the weeds that need no cultivation take over the garden and destroy it. ${ }^{2}$

To alter MacLennan's analogy slightly, justice is a flowering seed that must be cultivated, and we lawyers must be its diligent gardeners.

How do we go about being diligent gardeners in the cultivation of justice? We champion our profession's social contract. We strengthen the public's trust in us and in our profession. And we serve the public regularly and seek the good always.

We start by championing our profession's social contract. In Ontario, new members to the bar swear an oath: "I accept the honour and privilege, duty and responsibility of practising law as a barrister and solicitor in the Province of Ontario. I shall protect and defend the rights and interests of such persons

2. Hugh MacLennan, Voices in Time (McGill—Queen's University Press, 1980) at 121. 
as may employ me." "3 It continues: "I shall neglect no one's interest ... I shall not pervert the law to favour or prejudice any one." And then of overwhelming importance: "I shall seek to improve the administration of justice."

One of the best modern reformulations of professionalism in the law is the American Bar Association's Model Rules of Professional Conduct. It states: "A lawyer, as a member of the legal profession, is a representative of clients, an officer of the legal system and a public citizen having special responsibility for the quality of justice." 5 The A.B.A.'s Professional Committee is even sharper: "A professional lawyer is an expert in law pursuing a learned art in service to clients and in the spirit of public service, and engaging in these pursuits as part of a common calling to promote justice and public good." 6 These obligations- to our clients, to the public, and to justice-constitute the social contract that we have with our fellow citizens and our country. We must do our very best to live up to our contract each day, and not merely recite its conditions on one day.

All professions have their own social contracts, and each is made up of three principal elements. First, our profession is characterized by specialized knowledge that is taught formally and obtained by experience and under supervision. Second, the state gives us a right to have a monopoly, to control entry and exit standards and competence, and, to some degree, fees. Third, we have a responsibility to society that goes beyond the needs of specific clients. That's the deal we've made. If we fail to meet our obligations under that social contract, then citizens, through their elected representatives, will change it and redefine professionalism for us. Regulation and change will be forced upon us-quite possibly in forms that diminish or remove our self-regulatory privilege.

This is not an abstract discussion. The 2008 economic collapse is a powerful illustration of our profession's failure to meet our obligations under our social contract. The crisis shook the principles and institutions of the global economy to such an extent that we're still feeling and dealing with its aftershocks-socially and politically, as well as economically. This debacle reflected poorly not only on financial professionals, but also lawyers. How many in our profession papered the deals that involved fraudulent statements of assets, liabilities, income, valuation, and risk? On the flip side, how many lawyers sounded the alarm about conflict of interest in the web of financial transactions and instruments? Even before that, how many lawyers were silent in the face of a pattern of deregulation that left the U.S. economy naked to excessive leverage?

And what's especially surprising is that we had a precursor seven years earlier. The so-called "dot-com" crash of 2001 involving Enron, WorldCom, and others brought in the Sarbanes-Oxley framework of rules to regulate businesses that

3. Law Society of Ontario, By-law 4, s 21(1), available online: https://lawsocietyontario. azureedge.net/media/lso/media/legacy/pdf/b/by-law-4.pdf.

4. Ibid.

5. American Bar Association, Model Rules of Professional Conduct, Preamble, available online: https://www.americanbar.org/groups/professional_responsibility/publications/model_rules_of_ professional_conduct/model_rules_of_professional_conduct_preamble_scope/.

6. Ibid. 
operate in the U.S. ${ }^{7}$ This rigid framework replaced principles that corporate lawyers could interpret using their best judgement and highest ethic. It ended up being very costly to follow and of questionable effectiveness at the micro level. At the macro level, it encouraged an even greater system of excess to fall into place. In the wake of these crises, many in our profession stand guilty of focusing on doing the thing right operationally rather than doing the right thing ethically.

Which brings me to the next way in which we lawyers must be diligent gardeners: we strengthen must trust in our country. Trust writ large is fundamental to Canadian democracy. Our democracy depends on a rule of law that strives toward justice. Our rule of law depends on trust among citizens, and between citizens and the professionals and institutions that serve and represent them. Trust in these relationships means knowing certain basic truths exist. It doesn't mean those of us in democracies must agree upon absolutely everything. It does mean we must acknowledge the real state of the world: there is such a thing as truth; there are such things as facts; objective journalism is possible; history can be learned and learned from. If one does not consider anything to be true, if one believes facts are fungible commodities, if one thinks journalism is a lie and history a con, then the rule of law cannot work. And if the rule of law cannot work, then not only can we not use it to move closer to justice, our democracy and its institutions are doomed.

One pivotal action we lawyers can take to strengthen trust is to insist on doing the right thing and not merely the thing right. Put more formally, we must adhere to the moral imperative ahead of the operational.

Charles Dickens understood this principle well. At the centre of his novel Bleak House is Jaryndyce v Jaryndyce. ${ }^{8}$ The legal case deals with a large inheritance the disposition of which has droned on for generations. The matter is finally resolved by novel's end - but not before inflicting a cruel fate on each of the main characters. As for the inheritance, it has been rendered worthless, having been consumed by lawyers' fees. This satire of English legal proceedings is grounded in similar such cases in which the system and its professionals operated according to accepted rules and practices - things were done right - but evidence of the right thing being done was nowhere in sight. Dickens's treatment of this case reminds me of a cruel joke in the medical profession: "The operation was successful, but the patient died." It points to the arrogant delusion of those who believe an operation can be carried out flawlessly from a technical perspective even though the patient in question dies. Our placing of the operational imperative ahead of the moral isn't the stuff of literature only.

A contemporary instance is the administration of our courts. The Ontario court system has been slowed by an inordinate number of unproductive appearances and some of the longest court delays in the country. In his study of court processing times across Canada, Anthony Doob found that in cases where no bench

7. Sarbanes-Oxley Act of 2002 (Pub L 107-204, 116 Stat 745, enacted July 30, 2002).

8. Charles Dickens, Bleak House (Bradbury \& Evans, 1852). 
warrants were issued, Ontario had three times as many cases lasting more than eight months than did Alberta. ${ }^{9}$ And Alberta doesn't exactly stand at the top of the list of expeditious standards of court administration. Ontario has tried to reverse this trend through the Justice on Target program and methods such as streamlined disclosure, meaningful first appearances and dedicated prosecution. ${ }^{10}$ But years later the pace is still woefully slow.

Ontario isn't alone. Wide discrepancies exist all across Canada, both in our criminal and civil justice systems. The most recent World Justice Institute study ranked Canada twentieth out of the nations surveyed on access to civil justicebehind four of our G7 partners. Doob suggests that reducing these delays requires us to look hard at what he calls court cultures; that is, "shared expectations about how things should work" among judges, the accused, defence counsels, Crown attorneys and legal aid. ${ }^{11}$ We need to bring a sense of urgency to that shared culture, redefine professionalism and strengthen public trust in the law by making ourselves and our legal system more accessible to the public.

We must engage our most innovative thinking to regain our focus on serving the public. We can achieve this goal in many ways. Avoid the tort law morass of U.S. law. Simplify legal procedures and render them more cost-effective. Examine the scope of practice to unbundle activities that do not require legal professionals. And move the industry standard of pro bono work, including cases, teaching and law reform, from the current rate of less than three percent to 10, and build these "honourable hours" rigorously into the firm's revenue structure. If we wish to avoid having change forced upon us, we must embrace such new ideas and innovation.

Let me illustrate this point with an example for the medical profession. All Canadians would be wise to learn about the life of Dr. Thomas Roddick. After studying medicine at McGill University, Roddick went to Scotland where he graduated in surgery from the University of Edinburgh. There he studied under Joseph Lister, who was a pioneer in the use of carbolic acid to disinfect his operating rooms. Lister was so convinced of the medical benefits of carbolic acid as disinfectant that he damaged his hands and lost his ability to operate. Roddick returned to McGill to open a third operating room alongside the two senior professor surgeons who had taught him at McGill before his Edinburgh enlightenment. In his first two years of practice, his patients' mortality rate from surgery was less than two percent, all because of the disinfecting power of carbolic acid, with which he bathed his operating room. The two senior surgeons - who refused to use carbolic acid in their operating rooms-saw mortality rates of more than 20 percent among their patients due to cross-infection. At this point, Dr. William Osler, then a McGill professor, intervened and threatened

9. Cheryl Marie Webster \& Anthony N Doob, "Everything in Its Own Time: A Preliminary Examination of Court Processing Time in Canadian Criminal Court" (2003) Report presented to the Criminal Law Division, Department of Justice, Canada, Ottawa.

10. Ibid.

11. Anthony N Doob, "Headlines and Conclusions" (2002) 4:6 Criminological Rev 1 at 1. 
to publish the comparative statistics in the local newspapers if the two senior surgeons persisted in their refusal to use carbolic acid. They relented, and mortality rates dropped accordingly.

As lawyers, we can learn several lessons from this anecdote that we can apply to do the right thing and strengthen public trust in our profession. First, we must use best practices from other jurisdictions and be particularly open to the ideas and energy of younger members of our profession. Second, the most senior members of our profession must be prepared to intervene to ensure the public good. Third, we must create a culture of constant renewal and continuous improvement in practice and evidence-based learning. Fourth, we must ask ourselves what the public expects and what members of the public would say if they really knew what was going on in our profession. And fifth, we must serve the public good regularly and seek the good always.

That's my third admonition to you as legal professionals: seek the good. I've found in my career that lawyers can best seek the good by serving the public. We as a profession have traditionally done well in our appointments to the Bench. For the most part, we have an extremely high level of competence and trust; and - to the credit of our profession-our most accomplished colleagues are prepared to reduce their level of compensation to join the public service. We must build on this precious tradition of competence and integrity on the Bench. It's a precious and fundamental responsibility requiring constant vigilance to ensure that only the worthiest among us are elevated to the courts.

Lawyers are particularly well prepared for public service, yet we're substantially under-represented in it. So, we must do much more to ensure that all other areas of Canada's public service are able to draw from our profession. And we must ensure that the quality of the work, the opportunities, and the function of all professional levels are rewarded and appropriately respected in these areas. Part of the trick is to ensure that prospective law students and lawyers are fully aware of opportunities in the public service, and that we encourage movement back and forth between the practice of law and service to the public.

I've given you a lot to think about, so let me sum up what I'd like you to take away. The rule of law and a sense of justice aren't the same thing. At their best, a constitution, laws, and a court system are instruments we shape and wield to move closer to justice.

To borrow novelist Hugh MacLennan's analogy, justice is a seed that we lawyers must cultivate so that it grows and blooms. Being diligent gardeners in the cultivation of justice requires us to champion our profession's social contractmeeting and rising above our obligations under it. Being diligent gardeners in the cultivation of justice also requires us to be increasingly worthy of trust as lawyers and as a profession. We strengthen the public's trust in ourselves and our profession by doing the right thing ethically always and not merely the thing right operationally. Being diligent gardeners in the cultivation of justice requires us to serve the public and in doing so seek the good in ourselves, our fellow citizens and our country. 
The search for absolute justice is an impossible pursuit. We will never reach it. Yet we must never stop behaving as if we could. We must never stop striving toward justice-building trust in our profession, improving the rule of law, and seeking the good as we go.

The Right Honourable David Johnston (B.A., Harvard; LL.B., Cambridge; LL.B., Queen's, 1966) served as Canada's 28th Governor General from 2010-2017. Prior to that he served as President of the University of Waterloo, as Principal of McGill University, and as Dean of Western University's Faculty of Law. He has taught as a faculty member at Queen's University, the University of Toronto, and McGill University and is the recipient of 3 dozen honorary degrees or fellowships and the author or co-author of 30 books. 